This item was submitted to Loughborough's Research Repository by the author.

Items in Figshare are protected by copyright, with all rights reserved, unless otherwise indicated.

\title{
Changes in naïve and memory T-cells in elite swimmers during a winter training season
}

PLEASE CITE THE PUBLISHED VERSION

http://dx.doi.org/10.1016/j.bbi.2014.01.002

PUBLISHER

(C) Elsevier

VERSION

AM (Accepted Manuscript)

LICENCE

CC BY-NC-ND 4.0

\section{REPOSITORY RECORD}

Teixeira, Ana Maria, Luis Rama, Humberto M. Carvalho, Grasiely Borges, Tiago Carvalheiro, Michael Gleeson, Francisco Alves, Helder Trindade, and Artur Paiva. 2019. "Changes in Naïve and Memory T-cells in Elite Swimmers During a Winter Training Season”. figshare. https://hdl.handle.net/2134/14176. 
This item was submitted to Loughborough's Institutional Repository (https://dspace.lboro.ac.uk/) by the author and is made available under the following Creative Commons Licence conditions.

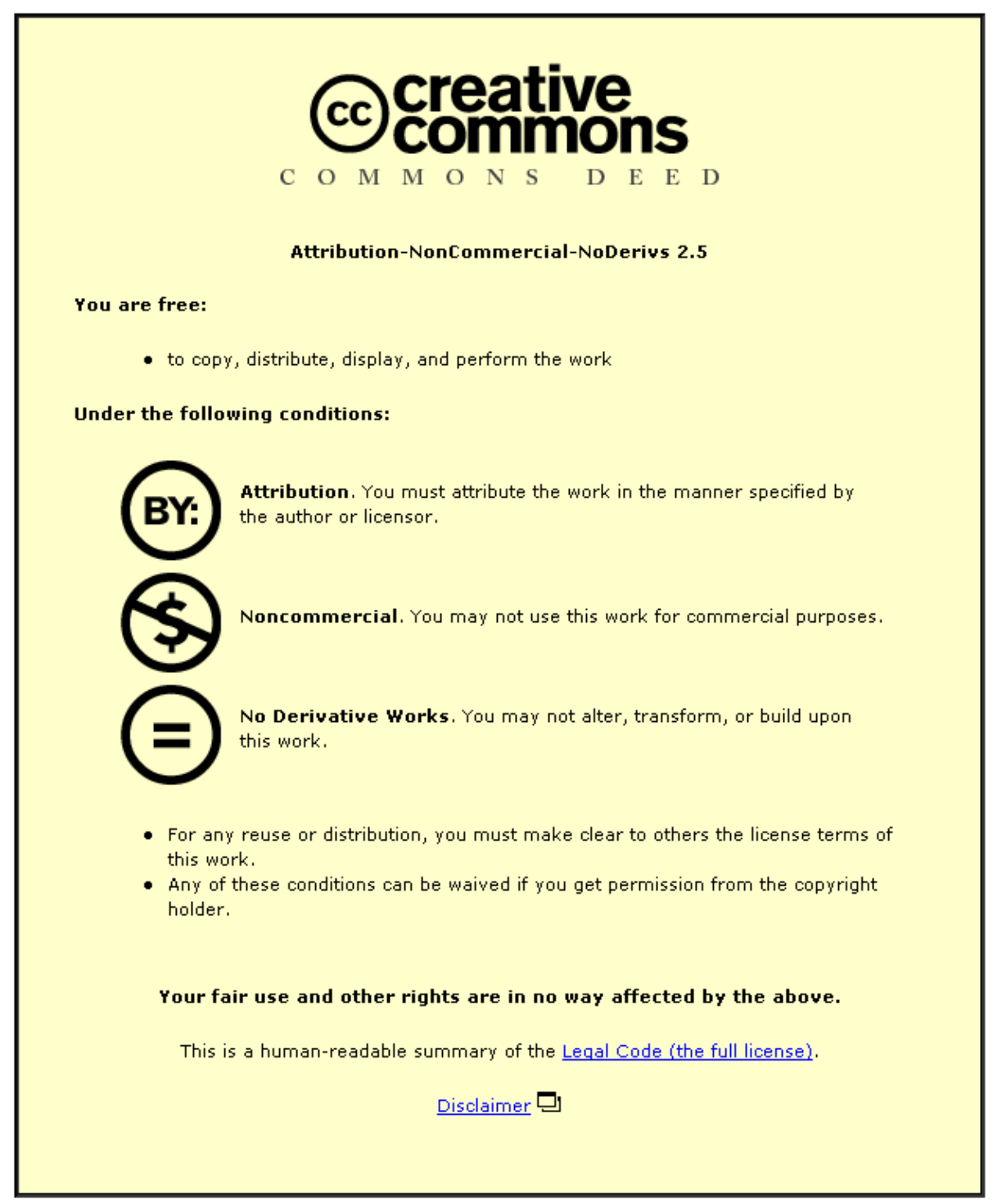

For the full text of this licence, please go to: http://creativecommons.org/licenses/by-nc-nd/2.5/ 


\section{ACCEPTED MANUSCRIPT}

Changes in naïve and memory T-cells in elite swimmers during a winter training season.

Ana Maria Teixeiraa Luís Ramaa, Humberto M Carvalhoa , Grasiely Borgesa, Tiago Carvalheirob, Michael Gleesonc, Francisco Alves ${ }^{\mathrm{d}}$, Hélder Trindade ${ }^{\mathrm{b}}$ and Artur Paivab

aResearch Center for Sport and Physical Activity, Faculty of Sport Sciences and Physical

Education, Coimbra University, Portugal.

${ }^{\text {b}}$ Portuguese Institute for Blood and Transplantation, Coimbra, Portugal.

'School of Sport, Exercise and Health Sciences, Loughborough University, UK

dFaculty of Human Kinetics, Technical University of Lisbon, Portugal

\section{Corresponding author}

Ana Maria Teixeira

FCDEF-UC, Estádio Universitário

Sta Clara

3040-156 Coimbra,

Portugal

\section{Abstract}

High intensity training regimens appear to put athletes at a higher risk of illness. As these have been linked to alterations in the proportions of differentiated $\mathrm{T}$ cells, how training load affects these populations could have important implications for athlete susceptibility to disease. This study examined the effect of a winter training season on the proportions of circulating naïve and memory $\mathrm{T}$ cells subsets of high competitive level swimmers.

Blood samples were taken at rest at 4 time-points during the season: before the start of the season ( $\mathrm{t} 0$-September), after 7 weeks of an initial period of gradually increasing training load (t1-November), after 6 weeks of an intense 
training cycle (t2-February) and 48 hours after the main competition ( $\mathrm{t} 3$-April) and from eleven non-athlete controls at 2 similar time-points ( $\mathrm{t} 2$ and $\mathrm{t} 3$ ).

CD4, CD8 and gamma-delta $(\gamma \delta) \mathrm{T}$ cells expressing the naïve (CCR7+CD45RA+), central-memory (CM-CCR7+CD45RA'), effector-memory (EM-CCR7-CD45RA-) and terminal effector (TEMRA-CCR7-CD45RA+) were quantified by flow cytometry. Statistical analyses were performed using multilevel modeling regression.

Both $\mathrm{T} \mathrm{CD} 4{ }^{+}$naïve and $\mathrm{CM}$ presented a linear increase in response to the first moment of training exposure, and had an exponential decrease until the end of the training exposure. As for TCD4+ EM, changes were observed from t2 until the end of the training season with an exponential trend, while TCD4+ TEMRA increased linearly throughout the season. $\mathrm{TCD}^{+}$naïve increased at $\mathrm{t} 1$ and decreased exponentially thereafter. TCD8+ TEMRA values decreased at $\mathrm{t} 1$ and increased exponentially until t3. $\gamma \delta \mathrm{T}$-EM had an increase at $\mathrm{t} 1$ and an exponential decrease afterwards. In contrast, $\gamma \delta$ T-TEMRA decreased at $\mathrm{t} 1$ and exponentially increased during the remaining 20 weeks of training.

An increase in TEMRA and EM T cells alongside a decrease in naïve T cells could leave athletes more susceptible to illness in response to variation in training stimulus during the season.

Keywords: training load; CCR7; CD45RA; $\gamma \delta$ T cells; exercise 


\section{Introduction}

Periods of heavy training appear to increase the incidence of upper respiratory tract symptoms (URS) in elite athletes (Bermon 2007) with infectious episodes often impairing training and performance and reducing the likelihood of success in high-level competition (Pyne et al, 2006). The mechanisms that could explain this increased susceptibility to infection are likely to be multi-factorial and could include alterations in the natural killer (NK) cell and T cell compartments. Such changes could be caused by repeated elevations of stress hormones (e.g. cortisol) and anti-inflammatory cytokines (e.g. interleukin-10) that occur in response to prolonged strenuous exercise during periods of heavy training.

There is only limited information on the effect of training load during a training season on the recirculation of lymphocytes between the tissues and the blood, their maturation status and how this may affect susceptibility to disease. Recently we reported that the numbers of CD56dim NK cells in the peripheral blood (PB) decrease during a swimming training season (Rama et al. 2013). This study suggests that periods of highly demanding training have a negative impact on innate immunity mediated by NK cell subsets, which could partially explain the higher frequency of URS observed during these training phases.

Another lymphocyte population with cytotoxic functions and important in host defense is the gamma-delta $(\gamma \delta) \mathrm{T}$ cell subset which are cells that possess a distinct T cell receptor (TCR) on their surface. Most T cells have a TCR composed of two glycoprotein chains called $\alpha$ and $\beta$ TCR chains (so called $\alpha \beta$ T cells). In contrast, $\gamma \delta$ T cells, have a TCR that is made up of one $\gamma$ chain and one $\delta$ chain. $\gamma \delta$ T cells represent approximately $5 \%$ of total T cells in PB, but comprise up to 
$50 \%$ of $\mathrm{T}$ cells in epithelial tissues, such as the lining of the gastro-intestinal tract where they act as sentinel cytotoxic cells involved in the elimination of bacterial infection (Nakasone et al. 2007) and wound repair (Girardi 2006). They are also have immunomodulatory and antigen presenting capabilities (Moser and Brandes 2006). They are known to be mobilized during acute psychological stress, exercise and $\beta$-adrenoreceptor agonist infusion (Anane et al. 2009). To date, no chronic studies on the effects of varying exercise training loads on circulating numbers of $\gamma \delta$ T cells have been reported.

It is possible to distinguish between naïve and memory/effector T cells subsets by the reciprocal expression of the CD45RA or CD45RO isoforms and the expression of CCR7 (Sallusto et al. 1999), a chemokine receptor that that controls homing to secondary lymphoid organs distinguishes human memory T cells into two functionally distinct subsets. CCR7- memory cells express receptors for migration to inflamed tissues and display immediate effector function. On the other hand, $\mathrm{CCR} 7^{+}$memory cells express lymph-node homing receptors and lack immediate effector function, but stimulate dendritic cells and differentiate into CCR7- effector cells upon secondary stimulation (Sallusto et al. 1999). Four different $\mathrm{T}$ cell subsets can be identified: one naïve $\mathrm{CD} 45 \mathrm{RA}{ }^{+} \mathrm{CCR} 7^{+}$and three memory subsets CD45RA-CCR7 ${ }^{+}$termed central memory (CM), CD45RA-CCR7termed effector memory (EM) and CD45RA ${ }^{+C C R} 7^{-}$termed terminally differentiated effector memory cells (TEMRA) (Sallusto et al, 1999). The CCR7+ subsets also express high levels of L-selectin (CD62L), the receptor for homing to peripheral and mesenteric lymph nodes, while the CCR7- subsets lack CD62L but 
express high levels of $\beta 1$ and $\beta 2$ integrins which are required for homing to inflamed tissues (Lanzavecchia and Sallusto 2005).

The aim of this study was to longitudinally examine the effect of chronic training on the levels of circulating naïve and memory $\mathrm{T}$ cells subsets in PB of high competitive level swimmers during a winter training season and to relate them to training load variation and the occurrence of Upper Respiratory Symptoms (URS). To this end we examined the changes in the proportion of $\alpha \beta$ and $\gamma \delta$ T cells that expressed the CD45RA and CCR7 antigens within the CD4+ and CD8+ T-cell subsets, at different times of the training season, including moments of increased training volume and intensity.

\section{Methods}

\subsection{Participants}

A group of 13 high level Portuguese swimmers, 10 males (17.2 \pm 1.1 years, $175 \pm$ $3 \mathrm{~cm}$ height and $64.6 \pm 4.0 \mathrm{~kg}$ weight $)$ and 3 females $(16.1 \pm 0.6$ years, $168 \pm 10$ cm height and $57.6 \pm 2.5 \mathrm{~kg}$ weight $)$ and a group of non-athletes, 7 males (18.6 \pm 1.1 years; $172 \pm 5 \mathrm{~cm}$ height and $79.9 \pm 14.6 \mathrm{~kg}$ weight $)$ and 4 females $(19.8 \pm 0.5$ years; $162 \pm 3 \mathrm{~cm}$ height and $58.5 \pm 6.9 \mathrm{~kg}$ weight) were recruited for this study which was approved by the Ethics and Human Subjects Review Board at the Faculty of Sports Science and Physical Education, University of Coimbra. All the participants and their tutors were informed of the objectives and procedures of the study and gave their written informed consent.

\subsection{Experimental design}


Training load, volume, intensity and participation in competition events, were monitored during 29 weeks of a winter swimming season from September to April. According to the usual methodologies used to quantify the training workload in swimming, the activities were categorized in different training zones. Dry land training activities were quantified by time and converted to swimming distance as proposed by Mujika and colleagues (Mujika et al., 1995). The distance values were multiplied by the intensity factor and totaled. The magnitude of the load was expressed in arbitrary units of load (AUL), quantified from the calculated sum of the volumes swam in each of the zones, multiplied by the respective intensity factor, and the total volume effectively completed (Mujika et al., 1995).

Blood samples were taken, at rest, at four specific times during the swimming winter season: before the start of the season and after an off season period of 5 to 6 weeks ( $\mathrm{t} 0$ ), after the first 7 weeks of gradual increasing the training load $(\mathrm{t} 1)$, in the $24^{\text {th }}$ week of training after an intense training cycle ( $\left.t 2\right)$, and in the $29^{\text {th }}$ week of training, 48 hours after a major competition ( $\mathrm{t} 3$ ).

During a similar winter period blood samples were obtained from the nonathlete group at two time points (February and April) matching the time points of the swimmers' group. These volunteers were not regularly involved in sport and did not spend more than 1 hour/week in recreational physical activities.

At the times of blood collection both swimmers and controls were in good health and were not using medication that could affect immune function and inflammation. All subjects were non smokers and non alcohol consumers (Spence et al. 2007). 
URS episodes in athletes and controls were monitored using daily log books, (1 episode was defined as repetition of more than two symptoms on at least two consecutive days). A new episode was considered after a minimum interval of 10 days following the previous one (Bishop, 2006). The list of symptoms was in accordance with the influenza-like-illness survey - European Influenza Surveillance Scheme (EISS) - and included cold, cough, nasal secretion, headache, sore throat, muscle pain, diarrhoea, abdominal pain, cold shivers, itchy eyes, sneezing and fever. Symptoms related to allergic episodes (itchy eyes, sneering], gastrointestinal or muscular pain related to injuries were careful analysed and discarded (Spence et al., 2007).

\subsection{Blood collection}

$20 \mathrm{~mL}$ of peripheral blood (PB) from an antecubital vein were collected by venepuncture into EDTA containing tubes, always at the same time of day, before the first afternoon workout of the week (16:00), after 30 minutes of resting in sitting position. A time lapse of 36 to 48 hours of rest after the last training session or competition was always maintained.

\subsection{Immunofluorescent staining}

Specific lymphocyte populations were identified by immunofluorescent staining of whole blood performing a four-colour immunophenotyping strategy. The following monoclonal antibodies (mAbs) combinations were used: CD45RA-FITC (clone HI 100; BD Pharmingen, San Diego, C.A. USA), CD3-PerCP-CY 5.5 (Clone SK7, BD Biosciences, San Jose, CA, USA), CD195 (CCR7) PE (clone 3D12; BD Pharmingen) and CD8-APC (clone: SK1;BD Bioscience). Another experiment was 
performed to $\gamma \delta \mathrm{T}$ cells characterization: CD45RA-FITC (clone HI 100; BD Pharmingen), CD3-PerCP-CY 5.5 (Clone SK7, BD Biosciences, San Jose, CA, USA), CD195 (CCR7) PE (clone 3D12; BD Pharmingen) avoyoTCR-APC (clone, B1; BD Pharmingen].

Briefly, PB aliquots were labelled and incubated for 10 minutes at room temperature in the dark. After this incubation period, $2 \mathrm{ml}$ of FACS Lysing Solution (BD Biosciences) diluted 1:10 (vol/vol) in distilled water was added and after 10 minutes of incubation the cells were washed with $2 \mathrm{ml}$ of PBS and resuspended in $0.5 \mathrm{ml}$ of $\mathrm{PBS}$, and stored in the dark at $4^{\circ} \mathrm{C}$, until acquisition in the flow cytometer.

\subsection{Flow cytometry data acquisition and analysis}

The data acquisition was performed in two consecutive steps in a FACSCalibur flow cytometer (BD Bioscences) equipped with an argon ion laser and a red diode laser In the first step, 20,000 events, corresponding to all nucleated cells present in the sample, were collected and information stored. In the second step, information was stored exclusively for those cells included in a live gate in the lymphocyte region containing 20.000 events. The FACSCalibur machine was routinely calibrated using Calibrite beads (BD Biosciences) and single labelled antibody tubes were used for further compensation adjustments. Total Lymphocytes were gated using forward versus side scatter.

Data analysis was performed in the Infinicyt version 1.4 software (Cytognos, Salamanca, Spain). Absolute counts were calculated using a dual platform methodology (flow cytometry and hematological cell analyser - Beckman Coulter LH 750, Miami, USA]. 
$\mathrm{T}$ lymphocytes were identified according to their positivity for CD3 and typical light scatter. Among positive CD3 cells, CD4 T cells were analyzed by the expression of CD3 and absence of CD8; instead, CD8 T cells were identified by the compression of both markers after exclusion of the $\gamma \delta \mathrm{T}$ cell subset according to their higher reactivity with anti-CD3 monoclonal antibody and typical light scatter. $\gamma \delta \mathrm{T}$ cells were identified by the positive expression for both CD3 and yo TCR. They were subsequently further differentiated into naive, CM, EM and TEMRA subsets by CD45RA expression in combination with CCR7.

\section{Statistical Analysis}

\subsection{Statistical analysis}

Initially visual inspection of stem-and-leaf plots was made to inspect the distribution of immunological responses with training. Descriptive statistics for all dependent variables at all measurement points are presented as mean \pm standard deviation. Changes in immunological responses as a consequence of training were examined based on multilevel modeling regression using a polynomial model. At Level 1, each participant's successive measurements over time were defined by an individual change trajectory, considering both the possibility of linear (linear term) and non-linear (linear term squared) changes, and random error. At level 2, differences in trajectories between groups of individuals were examined. All parameters were fixed with the exception of the constant (intercept term) linear change trajectory and squared change trajectory parameters, which were allowed to vary randomly at level 2 (between individuals). Inspection of autocorrelation between correlation between 
successive measurements over time and dependent variables variance at each measurement moment were considered in the adoption of covariance matrixes at both Level 1 and Level 2. Akaike information criterion (AIC), that take into account the different number of fitted parameters in the two model structures to be compared, as well as visual inspection of residual plots were used to determine the model's validity to fit immunological responses as a consequence of training. Significance was set at $p<0.05$. Statistical analyses were performed using mixed linear procedures available on SPSS version 20.0 (SPSS, Chicago, IL).

\section{Results}

\subsection{Training workload}

The training program followed the usual approach in swimming sport (Maglischo 2003), showing a gradual increment in training load in the first phase (first 7 weeks), followed by periods of increased intensity (from week 8 to week 24) while maintaining high volume during the central period of the season and a decrease of volume towards the end of the winter training season (week 30) in preparation for the main competition. Training data representing the weekly volume swum in each intensity zone is shown in table 1. Intensity was calculated as proposed by Mujika and colleagues (Mujika et al. 1996; Mujika et al. 1995). Training volume was significantly higher at $t 1$ and lower at $t 3$. Intensity increased significantly at $\mathrm{t} 2$ and remained elevated at $\mathrm{t} 3$ as was expected in the taper period just before the main winter competition $(\mathrm{p}<0.05)$.

\subsection{URS occurrence}


A total of 23 episodes that lasted $10.5(\mathrm{SD}=9.5)$ days corresponding to a mean of $1.8(\mathrm{SD}=1.7)$ URS episodes per athlete were reported during the study period. When looking at the 4 weeks before and the 2 weeks after the selected time points we found that $71 \%$ of the episodes occurred between the $7^{\text {th }}$ and $24^{\text {th }}$ weeks of training, i.e., the hardest training phases. Data analysis confirmed that the higher frequency of URS occurred during and soon after times of hard training, with some URS concurrent with a seasonal flu peak in December. The control group reported no URS episodes in the two weeks previous to the analyzed time-points. Other reported episodes out of this period of time were not considered as they occurred too much apart from the time of blood collection. No associations between changes in cell populations and experience of URS were found.

\subsection{Lymphocytes}

Table 2 displays the summary data and statistical analysis results for the lymphocyte and lymphocyte subset numbers and percentage at each time point analysed during the training season. Multilevel regression analysis for leukocytes, lymphocytes, $\mathrm{T}$ lymphocytes, $\mathrm{CD} 3^{+} \mathrm{CD} 4^{+}, \mathrm{CD}^{+}{ }^{+} \mathrm{CD} 8^{+}$and $\gamma \delta \mathrm{T}$ cell changes with training in the athletes are summarized in table 3 . All the variables showed no significant change with training at all measurement points. No changes were observed for any of the lymphocyte populations in the control group. However, when the athletes' baseline values were compared to those of the controls, differences were found for the number of CD3+T cells $(p<0.001)$, number and percentage of $\operatorname{TCD}^{+}(\mathrm{p}=0.012 ; \mathrm{p}=0.035)$ and number of $\gamma \delta \mathrm{T}$ cells $(p<0.001)$, these cell populations being higher for the control group. 


\subsection{CD8 and CD4 $\alpha \beta$ and $\gamma \delta$ T lymphocyte subsets}

The summary data and statistical results for the $\mathrm{CD} 8^{+}$and $\mathrm{CD} 4^{+} \alpha \beta$ and $\gamma \delta$ T lymphocyte subsets, as characterized by CD45RA and CCR7 expression are shown in tables 4 and 5 .

Multilevel regression analysis for $\mathrm{TCD}^{+}$subpopulation changes to training in the athletes are summarized in Table 4 and Figure 1 . With the exception of TCD4+ TEMRA, all variables show a curvilinear trend in response to training. Both TCD4+ naïve and TCD4+ CM presented a significant linear increase in response to the first moment of training exposure $(\mathrm{p}<0.05)$, and had a significant exponential decrease until the end of the training exposure $(\mathrm{p}<0.05)$. As for TCD4+ EM, no significant change was observed after the first 7 weeks of training $(\mathrm{p}<0.05)$, but an exponential increase was present at mean rate of $1.1 \%$ thereafter until the end of the training season $(p<0.05)$. A significant positive linear trend was observed for TCD4+ TEMRA in response to training $(\mathrm{p}<0.05)$.

Multilevel regression analysis for $\mathrm{TCD}^{+}$and $\gamma \delta \mathrm{T}$ subpopulation changes to training in the athletes are summarized in Table 5 and Figures 2 and 3. Both TCD8 ${ }^{+} \mathrm{CM}$ and $\mathrm{TDC}^{+}$EM subsets showed no significant response to training at all measurement points. TCD8 ${ }^{+}$naïve cells had a significant positive response to the first period of training, and a significant exponential decrease thereafter at a mean rate of $4.7 \%(\mathrm{p}<0.01)$. Also TCD8+ TEMRA cells had a non-linear response to training; however, initially their values significantly decreased and after the first 7 weeks of training exposure the responses increased exponentially at a rate of $3.4 \%(p<0.01)$. Interestingly, non-linear trends of response with similar 
magnitudes, but opposite directions were observed for $\gamma \delta \mathrm{T}$ EM and $\gamma \delta \mathrm{T}$ TEMRA subsets in response to training. $\gamma \delta \mathrm{T}$ EM cells had an increase with initial exposure to training and a significant exponential decrease afterwards until the end of the training season. In contrast, $\gamma \delta T$ TEMRA cells had a decrease after the first 7 weeks of training exponentially increased during the remaining 20 weeks of training.

When comparing the control to the athlete group at baseline, differences were found for the number of both $\mathrm{CD} 4^{+}$and $\mathrm{CD} 8^{+}$naïve (both $\mathrm{p}<0.001$ ), EM (both $\mathrm{p}<0.001$ ) and TEMRA (both $\mathrm{p}<0.001$ ) $\propto$ ( T T cell subsets. Naïve cell values were higher in the swimmers while the EM and TEMRA cell values were lower. The percentage of EM $\gamma \delta$ T cells was also lower in the swimmers $(\mathrm{p}<0.002)$ while the percentage for the TEMRA $\delta \gamma \mathrm{T}$ cell subset was higher.

Overall, the results from the multilevel models suggest there was significant residual variance within individual responses (level 1) to be explained for all dependent variables. With the exception of TCD8+ EM, $\gamma \delta$ T EM, $\gamma \delta$ T TEMRA and $\mathrm{CD}^{+} \mathrm{CD}^{+}$, there was no significant residual variance to be explained across individuals, i.e., at level 2 , indicating that the mean response is consistent between the athletes.

\section{Discussion}

This study examined the impact of training load during a 29-week swimming winter season on the percentages of naïve, central memory, effector memory and terminal effector memory within $\mathrm{CD} 4^{+}$and $\mathrm{CD} 8^{+} \mathrm{T}$-cell subsets, and $\gamma \delta \mathrm{T}$ cells, in a cohort of national level swimmers. It was found that the response to the first 7 
weeks of training, with a gradual increase in training volume, induced an increase in the percentages of both $\mathrm{CD}^{+}$and $\mathrm{CD}^{+}$naïve $\mathrm{T}$ cells, followed by a decrease until the end of the season. This was accompanied by an increase in the percentages of EM and TEMRA CD4+ cells throughout the season, and a decrease in the percentages of TEMRA CD8 ${ }^{+}$and $\gamma \delta \mathrm{T}$ cells in the first 7 weeks of training followed by an increase of these subpopulations until the end of the season. A study on the impact of a 6-month training preparation for and Ironman triathlon race on naïve and memory $\mathrm{T}$ cells (Cosgrove et al, 2012) also reported an increase with training in CD8+ effector memory (CD45RA-/CD45RO+) T-cells and $\mathrm{CD}^{+}$and $\mathrm{CD}^{+}$terminal effector memory (CD45RA+/CD45R0+) T cell-subsets. A recent study by Witard and colleagues (Witard et al. 2012) indicated that the mobilization and egress of CD8 ${ }^{+}$TEMRA cells and naïve CD8 ${ }^{+} \mathrm{T}$ cells were impaired by one week of high intensity training. It is possible that repeated bouts of high intensity training may lead to an increase of these populations in the athletes' $\mathrm{PB}$ and could also explain why only after the increase in training intensity (at week 24) the number of EM and TEMRA CD4 ${ }^{+}$and CD8 ${ }^{+}$cells increased in the $\mathrm{PB}$, whereas the training intensity done until week 7 was probably not high enough to induce a reduction in the egress of these cells from the PB during recovery periods (Witard et al. 2012). Several studies (Campbell et al. 2009; Simpson et al. 2007) have shown that high intensity acute exercise preferentially mobilizes TEMRA and $\mathrm{EM} C D 8^{+} \mathrm{T}$ cells into the $\mathrm{PB}$, including senescent T cells that express KLRG1 and CD57 on their surface. The fact that this highly citotoxic cells where shown by Witard and colleagues (Whitard et al, 2012) to have impaired egress capacity from the PB after one week of high intensity training, could explain why the maintenance for large periods of a high 
intensity training load could compromise the capacity of these cells to migrate to the peripheral tissues, which in turn, might be associated with compromised immume surveillance. Another explanation for the increase of memory and terminal effector memory $\mathrm{T}$ cells with training in our study could be the accumulation of these cells due to recent encounters of naïve or with preexisting CM T cells with antigens eliciting their differentiation into effector memory T cells. In fact both the absolute numbers of TCD $4^{+}$and TCD $8^{+}$naive (148 to 112,4 and 89,1 to 66,6 cells/ $\mu$ r respectively) and of $\mathrm{CD} 4^{+*}$ and $\mathrm{CD} 8^{*} \mathrm{CM} \mathrm{T}$ cells ( 36.7 to 19.3 and 14.23 to 9.8 cells/ $\mu$ respectively) decrease from baseline to t1. In fact our results show that $71 \%$ of the URS episodes reported were clustered around the more demanding training phases.

Maintaining a high magnitude of training load until the end of the training season could explain the may impaired naïve cell output and the increased percentage in terminally differentiated cells. Moreover it is possible that the stress induced by a major competition could also help increase the mobilization of terminally differentiated cells into the PB (Anane et al, 2009).

The higher percentage of naïve and the lower percentages of EM and TEMRA $\mathrm{CD}^{+}, \mathrm{EM} \mathrm{CD} 8^{+}$and $\gamma \delta \mathrm{T}$ cell-subsets in these athletes after 5 to 6 weeks of offseason training (summer vacations) when compared to the control group are consistent with the model proposed by Simpson (Simpson, 2010), that suggests that exercise may act as a mechanism for the depletion of senescent $\mathrm{T}$ cells, which accumulate with aging and take up "immune space" causing the naïve Tcell repertoire to shrink and increasing infection risk. Exercise would help remove these senescent cells by preferentially mobilizing them to the blood 
compartment, most probably under the influence of catecholamines, where the increased production of reactive oxygen species, glucocorticoids and proinflammatory cytokines by exercise, would expose them to proapoptopic stimuli. Several studies have documented blood lymphocytes DNA damage, increased oxidative stress-induced apoptosis and changes in cell surface death receptors after a single bout of acute exercise (Hoffman-Goetz (Hoffman-Goetz and Quadrilatero 2003; Kruger et al. 2009). These cells, together with undamaged naïve and memory $\mathrm{T}$ cells, would egress the blood compartment during the recovery phase of exercise and migrate to peripheral tissues. Some of these "marked" cells would then undergo apoptosis (Takahashi et al. 2005), thus creating vacant space. This creates a positive feedback loop that increases the naïve T-cell output from the thymus or sites of extrathymic T-cell development such as the liver and intestines. These new cells fill the vacant space and increase the naïve T-cell repertoire. This model is supported by the finding that aerobic fitness was associated with a lower age-related accumulation of senescent blood T-cells in men (Spielman et al, 2011). The higher values of TEMRA CD8+ T and $\gamma \delta \mathrm{T}$ cells in the athletes, found in our study, may be explained by the cumulative effect of exercise during several years of practice. When looking at the $\gamma \delta \mathrm{T}$-cell subset populations in the athletes we see an increase in the EM subset in the periphery while the TEMRA subset increases in the PB. Although in this study we did not stain for senescent markers like KLRG1, this could mean a better capacity for an immune response in the periphery while some of the less able to replicate senescent cells within the TEMRA subset are being targeted for apoptosis in the PB. 
Taken together and interpreted in the context of the model proposed by Simpson (Simpson 2011), our results suggest that fewer EM and TEMRA cells may be removed from the T-cell repertoire during long high-intensity training periods leaving the athletes more susceptible to illness. This however, maybe a small price to pay when considering the long term benefits of an increased naïve T-cell repertoire due to exercise practice.

\section{Acknowledgements}

We wish to thank Fátima Rosado for her help in sample collection. This work was supported by grant PTDC/DES/68647/2006 from the Portuguese Foundation for Science and Technology (FCT).

\section{References}

Anane LH, Edwards KM, Burns VE, Drayson MT, Riddell NE, van Zanten JJ, Wallace GR, Mills PJ, Bosch JA (2009) Mobilization of gammadelta T lymphocytes in response to psychological stress, exercise, and beta-agonist infusion. Brain Behav Immun 23: 823-829

Bermon S (2007) Airway inflammation and upper respiratory tract infection in athletes: is there a link? Exerc Immunol Rev 13: 6-14

Campbell JP, Riddell NE, Burns VE, Turner M, van Zanten JJ, Drayson MT, Bosch JA (2009) Acute exercise mobilises CD8+ T lymphocytes exhibiting an effector-memory phenotype. Brain Behav Immun 23: 767-775

Cosgrove C, Galloway SD, Neal C, Hunter AM, McFarlin BK, Spielmann G, Simpson RJ. (2012) The impact of 6-month training preparation for an Ironman triathlon on the proportions of naïve, memory and senescent T cells in resting blood. Eur J Appl Physiol. 112(8):2989-98

Girardi M (2006) Immunosurveillance and immunoregulation by gamma-delta T cells. J Invest Dermatol 126: 25-31 
Hoffman-Goetz L, Quadrilatero J (2003) Treadmill exercise in mice increases intestinal lymphocyte loss via apoptosis. Acta Physiol Scand 179: 289-297

Kruger K, Frost S, Most E, Volker K, Pallauf J, Mooren FC (2009) Exercise affects tissue lymphocyte apoptosis via redox-sensitive and Fas-dependent signaling pathways. Am J Physiol Regul Integr Comp Physiol 296: R1518-1527

Krzywkowski K, Petersen EW, Ostrowski K, Kristensen JH, Boza J, Pedersen BK (2001) Effect of glutamine supplementation on exercise-induced changes in lymphocyte function. Am J Physiol Cell Physiol 281: C1259-1265

Lanzavecchia A, Sallusto F (2005) Understanding the generation and function of memory T cell subsets. Curr Opin Immunol 17: 326-332

Maglischo E (2003) Swimming Fastest. The essential reference on technique, training, and program design. Human Kinetics

Morgado JM, Rama L, Silva I, de Jesus Inacio M, Henriques A, Laranjeira P, Pedreiro S, Rosado F, Alves F, Gleeson M, Pais ML, Paiva A, Teixeira AM (2012) Cytokine production by monocytes, neutrophils, and dendritic cells is hampered by long-term intensive training in elite swimmers. Eur J Appl Physiol 112: 471482

Moser B, Brandes M (2006) Gammadelta T cells: an alternative type of professional APC. Trends Immunol 27: 112-118

Mujika I, Busso T, Lacoste L, Barale F, Geyssant A, Chatard JC (1996) Modelled responses to training and taper in competitive swimmers. Medicine and science in sports and exercise 28: 251-258

Mujika I, Chatard JC, Busso T, Geyssant A, Barale F, Lacoste L (1995) Effects of training on performance in competitive swimming. . Can J Appl Physiol 20: 395406

Nakasone C, Yamamoto N, Nakamatsu M, Kinjo T, Miyagi K, Uezu K, Nakamura K, Higa F, Ishikawa H, O'Brien R L, Ikuta K, Kaku M, Fujita J, Kawakami K (2007) Accumulation of gamma/delta T cells in the lungs and their roles in neutrophilmediated host defense against pneumococcal infection. Microbes Infect 9: 251258

Pyne, D., W. Hopkins, et al. (2005). "Characterizing the individual performance responses to mild illness in international swimmers." Br J Sports Med 39(10): 752756

Rama L, Teixeira AM, Matos A, Borges G, Henriques A, Gleeson M, Pedreiro S, Filaire E, Alves F, Paiva A (2013) Changes in natural killer cell subpopulations over a winter training season in elite swimmers. Eur J Appl Physiol 113(4):859868 
Sallusto F, Lenig D, Forster R, Lipp M, Lanzavecchia A (1999) Two subsets of memory $\mathrm{T}$ lymphocytes with distinct homing potentials and effector functions. Nature 401: 708-712

Simpson RJ (2011) Aging, persistent viral infections, and immunosenescence: can exercise "make space"? Exerc Sport Sci Rev 39: 23-33

Simpson RJ, Florida-James GD, Cosgrove C, Whyte GP, Macrae S, Pircher H, Guy K (2007) High-intensity exercise elicits the mobilization of senescent $T$ lymphocytes into the peripheral blood compartment in human subjects. J Appl Physiol (1985) 103: 396-401

Spence L, Brown WJ, Pyne DB, Nissen MD, Sloots TP, McCormack JG, Locke AS, Fricker PA (2007) Incidence, Etiology, and Symptomatology of Upper Respiratory Illness in Elite Athletes. Med Sci Sports Exerc 39: 577-586

Spielmann G, Mcfarli BK, O'Connor P, Smith PJW, Pircher H, Simpson RJ (2011). Aerobic fitness is associated with lower proportions of senescent blood T-cells in man. Brain Behav Immun 25: 1521-1529

Takahashi A, Hanson MG, Norell HR, Havelka AM, Kono K, Malmberg KJ, Kiessling RV (2005) Preferential cell death of CD8+ effector memory (CCR7-CD45RA-) T cells by hydrogen peroxide-induced oxidative stress. J Immunol 174: 6080-6087

Witard OC, Turner JE, Jackman SR, Tipton KD, Jeukendrup AE, Kies AK, Bosch JA (2012) High-intensity training reduces CD8+ T-cell redistribution in response to exercise. Med Sci Sports Exerc 44: 1689-1697 
Table 1-Weekly training loads leading up to me points 1, 2 and 3.

\begin{tabular}{l|ccc} 
& \multicolumn{3}{|c}{ Time points } \\
\hline Training zones & T1 (week 7) & T2 (week 24) & T3 (week 29) \\
\hline Warm-up \& recovery $(\mathrm{m})$ & 14820 & 14816 & 9633 \\
Aerobic $(\mathrm{m})$ & 26925 & 29223 & 8673 \\
Anaerobic $(\mathrm{m})$ & 1805 & 2513 & 1200 \\
Sprint $(\mathrm{m})$ & 310 & 739 & 658 \\
\hline Total Volume $(\mathrm{m})$ & 42783 & 41228 & 20508 \\
Intensity (aul) & 12.3 & 14.1 & 13.8 \\
Dry land training (hours/week) & 3 & 4,5 & 3 \\
\hline
\end{tabular}

$m$ - meters; aul - arbitrary units of load 
Table 2. Mean (SD) cell number (cells/ $\mu \mathrm{l})$ and \% changes on leucocyte subpopulation and on naïve and memory T-cell subsets during a 29 -week winter season training in swimmers $(n=13)$ and control individuals $(n=11) *$ indicates statistical differences $(p<0.05)$ between athletes and controls at baseline based on student T-test analysis.

\begin{tabular}{|c|c|c|c|c|c|c|}
\hline & \multicolumn{4}{|c|}{ Athletes } & \multicolumn{2}{|c|}{ Controls } \\
\hline & Pre-season & 7 weeks & 24 weeks & 29 weeks & 24 weeks & 29 weeks \\
\hline Leukocytes (Cells $/ \mu \mathrm{L})$ & $7611(1489)$ & $9300(2326)$ & $8223(1519)$ & $8508(1728)$ & $6864(1306)$ & $7840(1497)$ \\
\hline Lymphocytes (\%) & $32.2(8.2)$ & $24.1(7.3)$ & $35.5(6.3)$ & $31.1(9.3)$ & $31.6(5.32)$ & $27.5(12.3)$ \\
\hline Lymphocytes (Cells $/ \mu \mathrm{L})$ & 2449 (877) & $2156(537)$ & $2911(689)$ & $2528(518)$ & $2166(365)$ & $2157(961)$ \\
\hline T Lymphocytes (\%) & $20.4(14.9)$ & $15.4(3.8)$ & $21.7(5.1)$ & $21.9(7.4)$ & $22.5(3.2)$ & $21.7(4.2)$ \\
\hline T Lymphocytes (Cells $/ \mu \mathrm{L})$ & $500(367)^{*}$ & $332(124)$ & $632(257)$ & $555(273)$ & $1520(251)^{*}$ & $1550(718)^{*}$ \\
\hline $\mathrm{CD}^{+} \mathrm{CD}^{+}(\%)$ & $60.6(5.3)$ & $62.2(7.1)$ & $58.8(6.8)$ & $56.2(9.7)$ & $58.9(6.8)$ & $59.9(5.6)$ \\
\hline $\mathrm{CD3}^{+} \mathrm{CD}^{+}($Cells $/ \mu \mathrm{L})$ & $297(201)$ & $203(74)$ & $367(145)$ & $297(125)$ & $902(212)$ & $939(479)$ \\
\hline $\mathrm{CD}^{+} \mathrm{CD}^{+}(\%)$ & $32.5(6.0)^{*}$ & $33.1(7.1)$ & $34.4(7.4)$ & $36.1(7.8)$ & $41.1(6.8)^{*}$ & $40.0(5.63)^{*}$ \\
\hline $\mathrm{CD}^{+}{ }^{+} \mathrm{CD} 8^{+}(\mathrm{Cell} s / \mu \mathrm{L})$ & $174(155)^{*}$ & $113(55)$ & $221(108)$ & $206(132)$ & $617(108)^{*}$ & $611(273)^{*}$ \\
\hline$\gamma \delta \mathrm{T}(\%)$ & $4.9(6.0)$ & $3.7(2.3)$ & $5.8(5.3)$ & $7.0(4.7)$ & $9.8(4.5)$ & $9.4(1.8)$ \\
\hline$\gamma \delta \mathrm{T}(\mathrm{Cells} / \mu \mathrm{L})$ & $19.6(18.0)^{*}$ & $12.6(10.0)$ & $38.3(46.1)$ & $46.9(55.5)$ & $138.9(49.5)^{*}$ & $141.8(59.2)^{*}$ \\
\hline $\mathrm{TCD}^{+}$naïve $\left(\mathrm{CD}^{2} 5 \mathrm{RA}^{+} \mathrm{CCR} 7^{+}\right)(\%)$ & $49.2(6.8)^{*}$ & $52.9(6.6)$ & $50.6(6.1)$ & $48.4(7.6)$ & $21.7(7.0)^{*}$ & $33.2(9.5)^{*}$ \\
\hline $\mathrm{TCD}^{+}{ }^{+}$naïve $\left(\mathrm{CD} 45 \mathrm{RA}^{+} \mathrm{CCR} 7^{\dagger}\right)(\mathrm{Cells} / \mu \mathrm{L})$ & $146.1(20.2)^{*}$ & $107.4(13.4)$ & $185.7(22.4)$ & $143.8(22.6)$ & $195.7(63.1)^{*}$ & $311.7(89.2)^{*}$ \\
\hline TCD4+ CM (CD45RA CCR7 $)(\%)$ & $12.2(2.5)^{*}$ & $9.1(2.0)$ & $12.3(3.9)$ & $14.9(4.6)$ & $27.6(6.5)^{*}$ & $43.1(9.8)^{*}$ \\
\hline TCD4+ CM (CD45RA $\left.{ }^{-\mathrm{CCR} 7}\right)(\mathrm{Cells} / \mu \mathrm{L})$ & $36.2(7.4)^{*}$ & $18.5(4.1)$ & $45.1(14.3)$ & $44.3(13.7)$ & $249.0(58.6)^{*}$ & $404.7(92.0)^{*}$ \\
\hline $\mathrm{TCD} 4+\mathrm{EM}\left(\mathrm{CD} 45 \mathrm{RA}^{\bullet} \mathrm{CCR} 7^{+}\right)(\%)$ & $35.6(5.5)^{*}$ & $36.5(6.4)$ & $34.3(5.4)$ & $30.8(5.4)$ & $41.9(14.8)^{*}$ & $25.8(16.0)^{*}$ \\
\hline 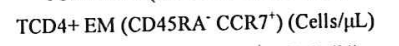 & $105.7(16.3)^{*}$ & $74.1(13.0)$ & $125.9(19.8)$ & $91.5(16.0)$ & $377.9(133.5)^{*}$ & $242.3(150.2)^{*}$ \\
\hline TCD4+ TEMRA CD45RA+ CCR7 (\%) & $2.9(2.0)^{*}$ & $1.5(0.8)$ & $4.5(8.1)$ & $5.9(3.9)$ & $11.7(4.5)^{*}$ & $5.7(4.3)^{*}$ \\
\hline TCD4+ TEMRA CD45RA ${ }^{+}$CCR7 (Cells $\left./ \mu \mathrm{L}\right)$ & $8.6(5.9)^{*}$ & $3.1(1.6)$ & $16.5(29.4)$ & $17.5(11.6)$ & $105.5(40.6)^{*}$ & $53.5(40.4)^{*}$ \\
\hline TCD8+ naïve $\left(\mathrm{CD}^{2} 5 \mathrm{RA}^{+} \mathrm{CCR} 7^{+}\right)(\%)$ & $48.8(12.2)^{*}$ & $57.3(11.4)$ & $50.2(11.0)$ & $39.8(14.4)$ & $25.8(9.1)^{*}$ & $31.5(10.9)$ \\
\hline TCD8+ naĩve $\left(\mathrm{CD}^{2} 5 \mathrm{RA} \mathrm{A}^{+} \mathrm{CCR} 7^{+}\right)(\mathrm{Cells} / \mu \mathrm{L})$ & $84.9(11.8)^{*}$ & $64.7(12.9)$ & $110.9(24.3)$ & $82.0(29.7)$ & $159.5(40.6)^{*}$ & $193.0(66)^{*}$ \\
\hline TCD8+ CM (CD45RA CCR7) $(\%)$ & $7.8(2.6)$ & $8.4(2.4)$ & $7.8(3.2)$ & $7.5(3.4)$ & $7.1(2.1)$ & $9.6(4.0)$ \\
\hline TCD8+ CM (CD45RA CCR7) $($ Cells $/ \mu \mathrm{L})$ & $13.5(4.5)^{*}$ & $9.5(2.7)$ & $17.2(7.1)$ & $15.5(7.0)$ & $43.8(13.0)^{*}$ & $58.7(24.4)^{*}$ \\
\hline TCD8+ EM (CD45RA $\left.{ }^{-} \mathrm{CCR}^{+}\right)(\%)$ & $16.2(5.3)^{*}$ & $16.8(5.2)$ & $16.8(5.5)$ & $21.0(13.6)$ & $53.4(6.9)^{*}$ & $39.5(8.6)^{*}$ \\
\hline TCD8+ EM (CD45RA CCR7†) (Cells/ $\mu \mathrm{L})$ & $28.2(9.2)^{*}$ & $19.0(5.9)$ & $37.1(12.2)$ & $43.3(28.0)$ & $329.5(42.5)^{*}$ & $241.3(52.5)^{*}$ \\
\hline TCD8+ TEMRA CD45RA CCR7 (\%) & $24.8(12.6)^{*}$ & $17.4(9.8)$ & $25.5(11.3)$ & $31.7(14.9)$ & $17.6(8.0)$ & $17.2(10.5)$ \\
\hline TCD8+ TEMRA CD45RA ${ }^{+}$CCR7 (Cells/ $\left.\mu \mathrm{L}\right)$ & $43.2(21.9)^{*}$ & $19.7(11.0)$ & $56.4(24.0)$ & $65.3(30.7)$ & $108.6(49.4)^{*}$ & $105.1(64.2)^{*}$ \\
\hline$\gamma \delta \mathrm{T}$ EM $\left(\mathrm{CD} 45 \mathrm{RA}^{-} \mathrm{CCR} 7^{+}\right)(\%)$ & $48.5(15.4)^{*}$ & $65.0(15.4)$ & $53.8(11.3)$ & $57.0(15.2)$ & $74.8(21.0)^{*}$ & $76.1(13.7)^{*}$ \\
\hline$\gamma \delta \mathrm{T} \mathrm{EM}\left(\mathrm{CD} 45 \mathrm{RA}^{-} \mathrm{CCR}^{+}\right)\left(\mathrm{Cell}^{\mathrm{s}} / \mu \mathrm{L}\right)$ & $9.5(3.0)^{*}$ & $8.2(1.9)$ & $20.6(4.3)$ & $26.7(7.0)$ & $103.9(29.0)^{*}$ & $108.9(19.4)^{*}$ \\
\hline$\gamma \delta \mathrm{T}$ TEMRA CD45RA ${ }^{+}$CCR7 $(\%)$ & $51.5(15.4)^{*}$ & $35.0(15.4)$ & $46.2(11.3)$ & $43.0(15.2)$ & $25.1(18.8)^{*}$ & $24.0(13.6)^{*}$ \\
\hline$\gamma \delta \mathrm{T}_{\mathrm{TEMRA}}$ CD $45 \mathrm{RA}^{+}$CCR7 (Cells $\left./ \mu \mathrm{L}\right)$ & $10.1(3.0)^{*}$ & $4.4(1.9)$ & $17.7(4.3)$ & $20.2(7.0)$ & $34.8(26.0)^{*}$ & $34.0(19.3)^{*}$ \\
\hline
\end{tabular}


Table 3. Multilevel regression analysis of Leukocytes, Lymphocytes, $\mathrm{T}$ Lymphocytes, $\mathrm{CD} 3^{+} \mathrm{CD} 4^{+}, \mathrm{CD} 3^{+} \mathrm{CD} 8^{+}$and $\gamma \delta \mathrm{T}$ cell changes with training.

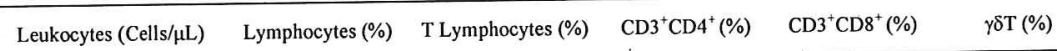

Variance-Covariance Matrix of Random Variables

Level 1 (within individuals)

Intercept

$8169(328)^{* *} \quad 29.6(1.8)^{* *} \quad 17.2(1.2)^{* *} \quad 61.9(1.5)^{* *} \quad 32.2(1.3)^{* *} \quad 4.1(1.0)^{* *}$

Linear growth

161 (237)

$0.8(1.1)$

$1.2(0.7)$

$-1.7(0.9)$

$1.9(1.2)$

$0.8(0.6)$

Variance-Covariance Matrix of Random Variables

Level 1 (within individuals)

Repeated measures variance

$2324782(580650)^{* *} \quad 53.9(13.0)^{* *} \quad 22.0(5.4)^{* *} \quad 33.3(8.4)^{* *} \quad 10.9(3.4)^{* *} \quad 14.6(3.9)^{* *}$

Level 2 (between individuals)

\begin{tabular}{|c|c|c|c|c|c|c|}
\hline Variance & $269895(182766)$ & $3.5(3.5)$ & $3.0(1.8)$ & $5.0(3.1)$ & $13.9(6.3)^{*}$ & $2.1(1.5)$ \\
\hline -2 Restricted Log Likelihood & 897 & 361 & 320 & 342 & 318 & 301 \\
\hline Akaike's Information Criterion & 901 & 366 & 324 & 346 & 322 & 305 \\
\hline
\end{tabular}

${ }^{* *} \mathrm{p} \leq 0.01 ;{ }^{*} \mathrm{p} \leq 0.05$ 
Table 4. Multilevel regression analysis for $\mathrm{CD} 4+\mathrm{T}$ cell subpopulations changes to training in swimming athletes.

\begin{tabular}{|c|c|c|c|c|}
\hline & $\begin{array}{c}\text { TCD4+ naĩve } \\
\left({\left.\mathrm{CD} 45 \mathrm{RA}^{+} \mathrm{CCR} 7^{+}\right)(\%)}(\%)\right.\end{array}$ & $\begin{array}{c}\text { TCD4+CM } \\
\left(\mathrm{CD}_{5} 5 \mathrm{RA}^{-} \mathrm{CCR} 7^{+}\right)(\%) \\
\end{array}$ & $\begin{array}{c}\text { TCD4+ EM } \\
(\text { CD45RA CCR7) }(\%) \\
\end{array}$ & $\begin{array}{c}\text { TCD4+ TEMRA } \\
\left({\left.\text { CD } 45 R A^{+} \text {CCR7 }\right)(\%)}\right.\end{array}$ \\
\hline \multicolumn{5}{|l|}{ Fixed Explanatory Variables } \\
\hline \multicolumn{5}{|l|}{ Exponent value (standard error) } \\
\hline Intercept & $49.5(1.4)^{* *}$ & $11.9(0.8)^{* *}$ & $35.7(1.2)^{* *}$ & $1.9(0.9)^{*}$ \\
\hline Linear growth & $4.0(2.0)^{*}$ & $-3.2(1.3)^{*}$ & $1.6(1.7)$ & $1.2(0.6)^{*}$ \\
\hline Quadratic growth & $-1.5(0.6)^{*}$ & $1.4(0.4)^{* *}$ & $-1.1(0.5)^{*}$ & - \\
\hline \multicolumn{5}{|c|}{ Variance-Covariance Matrix of Random Variables } \\
\hline Level 1 (within individuals) & & & & \\
\hline Repeated measures variance & $18.1(5.1)^{* *}$ & $8.8(2.1)^{* *}$ & $19.9(11.1)^{* *}$ & $14.3(3.2)^{* *}$ \\
\hline \multicolumn{5}{|l|}{ Level 2 (between individuals) } \\
\hline Variance & $3.6(1.9)^{*}$ & $0.7(0.5)$ & $5.6(0.0)$ & $1.5(0.9)$ \\
\hline -2 Restricted Log Likelihood & 322 & 270 & 309 & 297 \\
\hline Akaike's Information Criterion & 326 & 274 & 313 & 301 \\
\hline
\end{tabular}

${ }^{* *} p \leq 0.01 ;{ }^{*} p \leq 0.05$ 
Table 5. Multilevel regression analysis for CD8+ and Gamma-delta $\mathrm{T}$ cell subpopulations changes to training in swimming athletes.

\begin{tabular}{|c|c|c|c|c|c|c|}
\hline & $\begin{array}{c}\text { TCD8+ naïve } \\
\left(\text { CD45RA }^{+} \text {CCR } 7^{+}\right)(\%)\end{array}$ & $\begin{array}{c}\text { TCD8+CM } \\
\left({\text { CD } 45 R A^{-} \text {CCR7 }}^{+}\right)(\%) \\
\end{array}$ & $\begin{array}{c}\text { TCD8+EM } \\
\left(\text { (CD45RA }^{-} \text {CCR7) }(\%)\right. \\
\end{array}$ & $\begin{array}{c}\text { TCD8+ TEMRA } \\
\left(\text { CD45RA }^{+} \text {CCR7 } 7^{-}\right)(\%) \\
\end{array}$ & 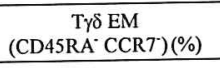 & 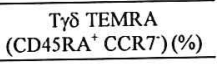 \\
\hline \multicolumn{7}{|l|}{ Fixed Explanatory Variables } \\
\hline \multicolumn{7}{|l|}{ Exponent value (standard error) } \\
\hline Intercept & $48.9(3.2)^{* *}$ & $15.5(1.5)^{* *}$ & $8.1(0.5)^{* *}$ & $23.9(2.3)^{* *}$ & $50.9(3.5)^{* *}$ & $49.1(3.5)^{* *}$ \\
\hline Linear growth & $11.1(3.7)^{* *}$ & $1.4(1.5)$ & $-0.1(0.8)$ & $-7.4(3.3)^{*}$ & $11.1(5.2)^{*}$ & $-11.1(5.2)^{*}$ \\
\hline Quadratic growth & $-4.7(1.1)^{* *}$ & - & - & $3.4(0.9)^{* *}$ & $-3.2(1.6)^{*}$ & $3.2(1.6)^{*}$ \\
\hline \multicolumn{7}{|c|}{ Variance-Covariance Matrix of Random Variables } \\
\hline \multicolumn{7}{|l|}{ Level 1 (within individuals) } \\
\hline Repeated measures variance & $134.3(55.1)^{*}$ & $30.8(7.8)^{* *}$ & $3.4(0.9)^{* *}$ & $44.9(13.0)^{* *}$ & $129.8(35.3)^{* *}$ & $129.8(35.3)^{* *}$ \\
\hline \multicolumn{7}{|l|}{ Level 2 (between individuals) } \\
\hline Variance & $3.0(5.9)$ & $8.2(4.1)^{*}$ & $1.1(0.5)^{*}$ & $28.2(13.1)^{*}$ & $23.9(15.1)$ & $23.9(15.1)$ \\
\hline -2 Restricted Log Likelihood & 381 & 345 & 238 & 374 & 401 & 401 \\
\hline Akaike's Information Criterion & 389 & 349 & 242 & 378 & 405 & 405 \\
\hline
\end{tabular}

${ }^{* *} \mathrm{p} \leq 0.01 ;{ }^{*} \mathrm{p} \leq 0.05$ 

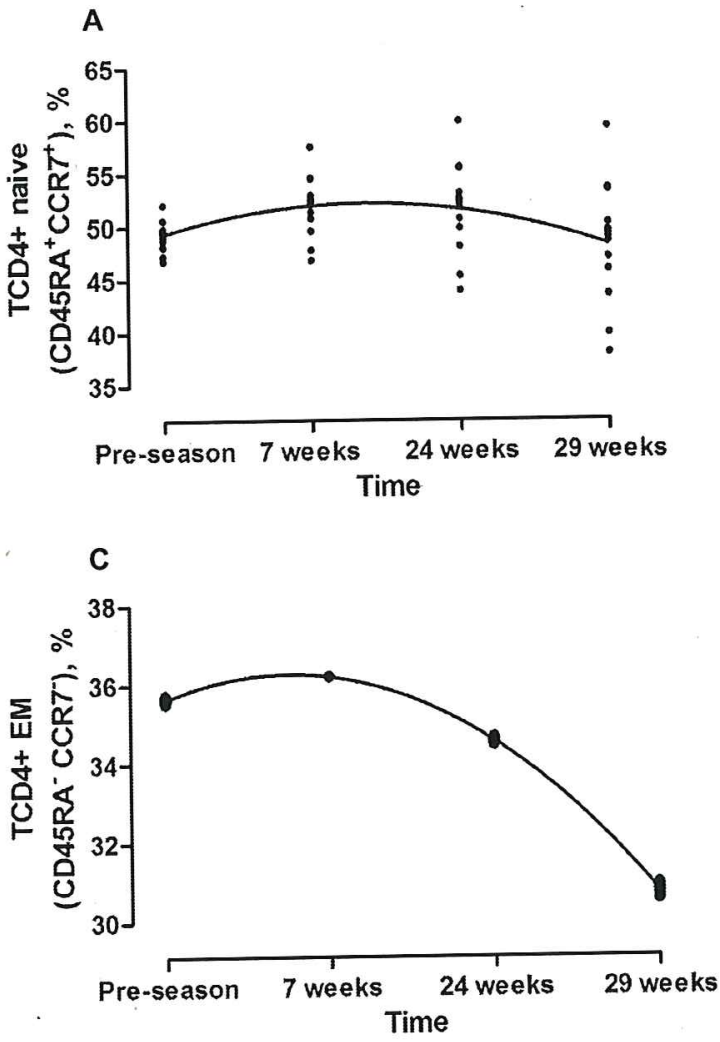

B

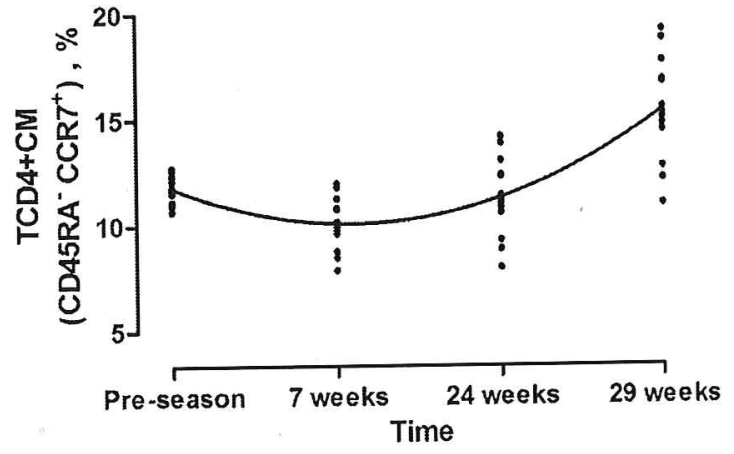

D

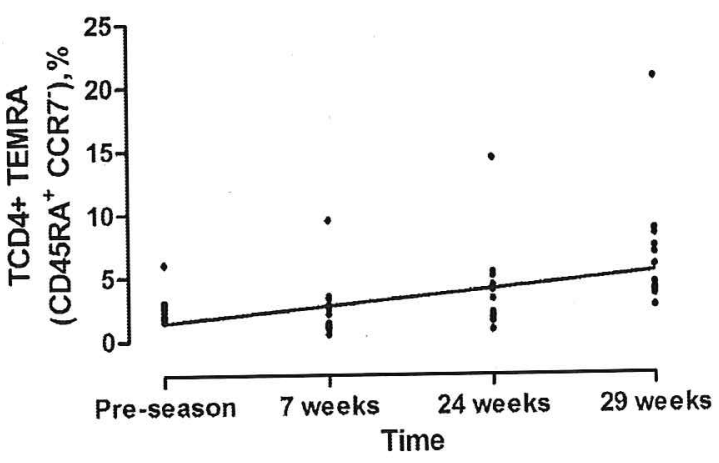

Figure 1. Mean changes in naïve and memory $C D 4^{+}$T-cell subsets during a 29-week winter training season in swimmers. Panel $A$ : significant increase in TCD4 ${ }^{+}$naïve cells until the first 7 weeks, followed by significant exponential decrease in cell expression throughout the remaining training season ( $p \leq 0.05)$; Panel B: significant decrease in TCD4 ${ }^{+}$CM cells until the first 7 weeks $(p \leq 0.05)$, followed by significant exponential increase in cell expression throughout the remaining training season ( $p \leq 0.01)$; Panel $C$ : significant exponential decrease in TDCD4+ EM cells expression only after the first 7 weeks of training and until the end of the training season ( $p \leq$ 0.01); Panel C: significant linear increase in TDCD4 ${ }^{+}$TEMRA cells expression throughout training season $(p \leq 0.05)$. 

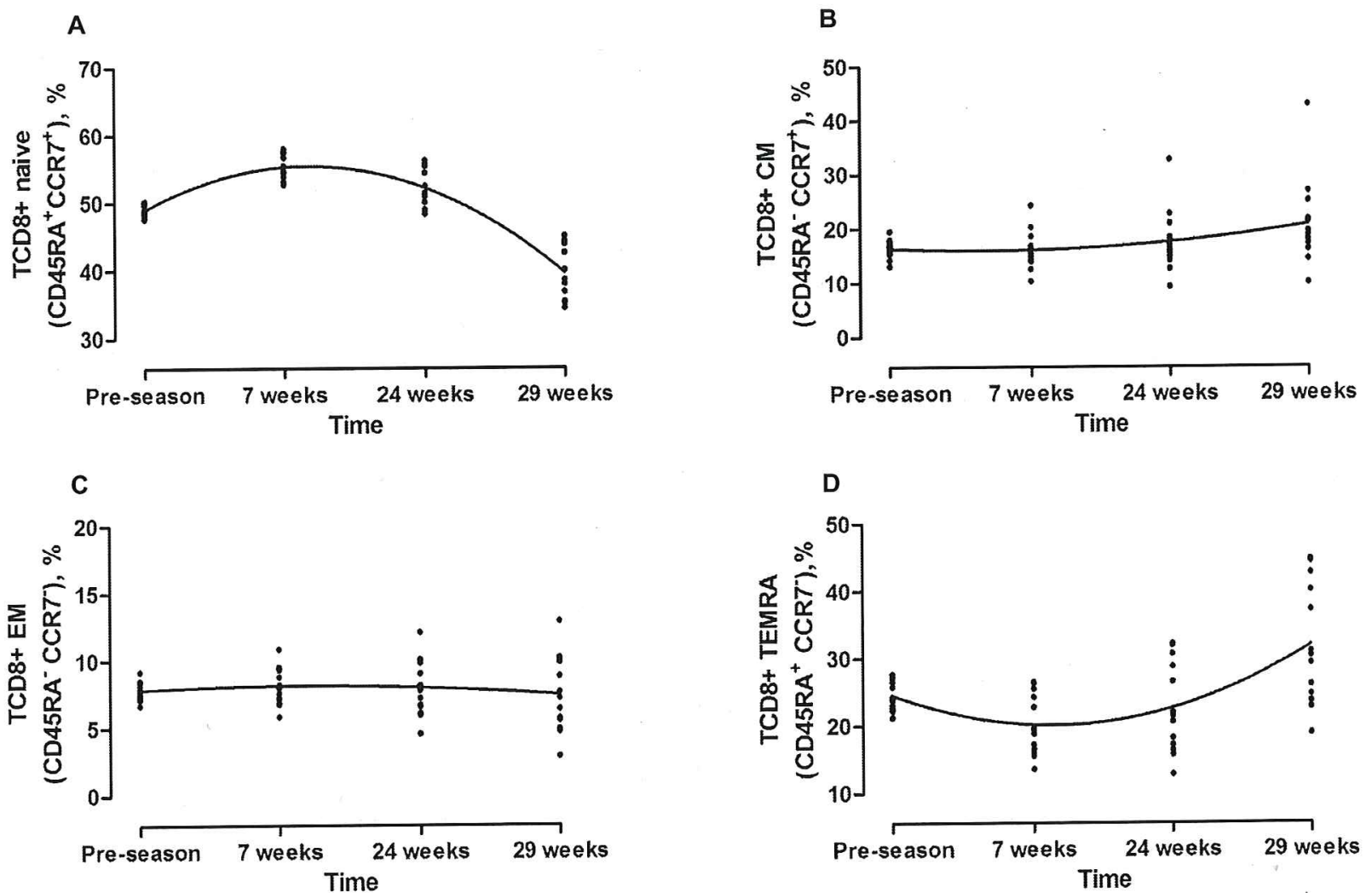

Figure 2. Mean changes in naïve and memory $C D 8^{+}$T-cell subsets during a 29-week winter training season in swimmers. Panel A: significant increase in TCD8 ${ }^{+}$naïve cells until the first 7 weeks, followed by significant exponential decrease in cell expression throughout the remaining training season ( $p \leq 0.01$ ); Panel B: no significant changes in TCD $8^{+} \mathrm{CM}$ cells throughout the training season ( $p>0.05$ ); Panel $C$ : no significant changes in TCD8 ${ }^{+}$EM cells throughout the training season $(p>0.05)$; Panel $D$ : significant decrease in TCD8 ${ }^{+}$TEMRA cells until the first 7 weeks $(p \leq 0.05)$, followed by significant exponential increase in cell expression throughout the remaining training season $(p \leq 0.01)$. 

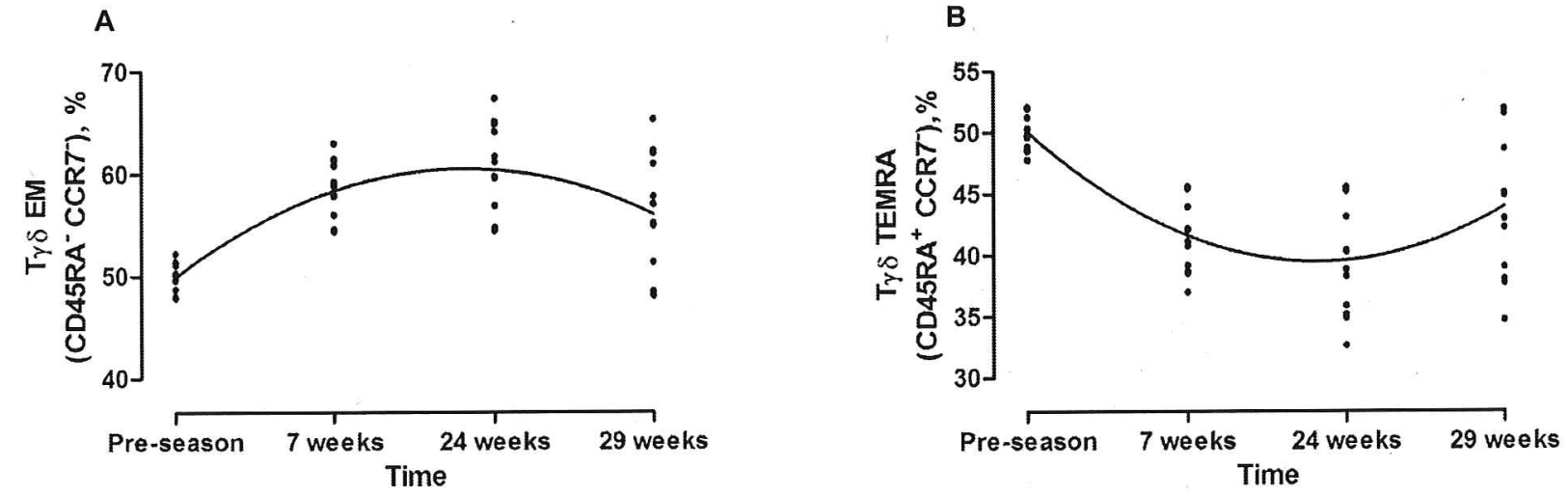

Figure 3. Mean changes in memory $\gamma \delta$ T-cell subsets in during a 29-week winter training season in swimmers. Panel A: significant increase in T $\gamma \delta$ EM cells until the first 7 weeks, with the significant exponential exponent indicating attainment of a plateau between 7 th and 24th weeks of training and a decrease thereafter ( $p \leq$ 0.05); Panel B: significant decrease in T $\gamma \delta$ TEMRA cells until the first 7 weeks, with the significant exponential exponent indicating a deceleration of the decreases in these cells' expression between the 7th and 24th week and an increase after the 24th week until the end of the training season $(p \leq 0.05)$. 